\title{
Synthesis and optical properties of $\mathrm{CdSe} / \mathrm{CdS}$ core/shell nanocrystals
}

\author{
A. GAdAlla ${ }^{1}$, M. S. AbD El-SADEK ${ }^{2}$, R. HAMOOD $^{1, *}$ \\ ${ }^{1}$ Physics Department, Faculty of Science, Assiut University, Egypt \\ ${ }^{2}$ Nanomaterial Lab., Physics Department, Faculty of Science, South Valley University, Qena, Egypt
}

\begin{abstract}
This paper attempts to describe an effective method for producing a composite of quantum dots consisting of CdSe (core) with CdS (shell). This nanoparticles composite was synthesized from modified organometallic precursors. The sizes of the nanoparticles were estimated from X-ray diffraction data using Debye-Scherer formula and compared with high resolution electron microscopy (HRTEM) and optical spectra. The shape of CdSe/CdS NPs is nearly spherical and revels that the CdS shell with the thickness $\sim 0.6 \mathrm{~nm}$ almost fully covers the CdSe core (higher contrast). Using UV-Vis spectroscopy, a systematic red shift in the absorption and emission spectra was observed after the deposition of CdS which confirms the shell growth over the $\mathrm{CdSe}$ core. In the $\mathrm{CdSe} / \mathrm{CdS}$ core/shell structure, the holes are confined to the core, while the electrons are delocalized as a result of similar electron affinities of the core and the shell. The increased time of synthesis resulted in shell thickness increase. The observed properties of prepared CdSe/CdS QDs demonstrate the capability of the nanocomposite for using in the optoelectronics and photonics devices.
\end{abstract}

Keywords: CdSe/CdS core/shell; quantum dots; optical spectra; HRTEM; X-rays

\section{Introduction}

Semiconductor nanocrystals quantum dots (QDs) whose radii are smaller than the bulk exciton Bohr radius constitute a class of materials intermediate between molecular and bulk forms of matter. They represent one of the most exciting nanoscience fields of the current century, because of drastic changes in most material properties dependent on the nanocrystal size, due to quantum confinement [1, 2]. Among numerous semiconductor materials, cadmium selenide $(\mathrm{CdSe})$ is one of the most versatile quantum dot materials as its emission peak can be anywhere in the visible spectrum which enables its potential applications ranging from solar-light sensitizers to multicolor fluorescent markers in biological systems [3].

In general, the luminescent NCs can be prepared either in an aqueous medium [4] or by an organometallic route [5], however, both strategies have their own advantages and drawbacks [6]. Usually, NCs grown in an aqueous medium

*E-mail: rananom77@yahoo.com do not possess the degree of crystallinity of the organometallically prepared QDs where high annealing temperatures are used during the synthesis $[4,7]$.

In previous research [8-10], CdSe and QDs were prepared by using many capping agents to prevent irreversible aggregation, coagulation and fusion of quantum dots. The capping agent is basically prepared from stearic acid, oleic acid [10], tri(n-octyl)phosphine (TOP) [11] and tri(n-octyl)phosphine oxide (TOPO) [12]. Thus, the synthesis of CdSe nanocrystals from cadmium oxide $(\mathrm{CdO})$ and tri(n-octyl) phosphine selenide (TOPSe) at high temperature in TOPO-TOP mixture yields highly crystalline $\mathrm{CdSe}$ nanocrystals with the sizes tunable from $1.7 \mathrm{~nm}$ to $15 \mathrm{~nm}$ [5]. Introducing hexadecylamine (HDA) as a co-surfactant to the TOPO-TOP stabilizing mixture narrows the size distribution of CdSe nanocrystals during their growth and allows a considerable improvement of their photoluminescence (PL) properties [13].

Core/shell type composite quantum dots exhibit novel properties which make them attractive from 
both experimental and practical point of view [1418]. Coating of nanocrystallites with high bandgap inorganic materials has been shown to improve the photoluminescence quantum yield due to elimination of surface nonradiative recombination defects. Some examples of core/shell quantum dot structures reported earlier include $\mathrm{CdS}$ on $\mathrm{CdSe}$ or CdSe on CdS [14], ZnS grown on CdS [15]. $\mathrm{ZnS}$ on CdSe and inverse structures [16] as well as $\mathrm{CdS} / \mathrm{HgS} / \mathrm{CdS}$ quantum dots [17]. Recently, Hines et al. [18] reported making CdSe/ZnS nanocrystallite whose room temperature fluorescence quantum yield was $50 \%$.

Core/shell QDs are divided into type-I and typeII like bulk semiconductors, depending on their band gap structure. In type-I structure, both the conduction and valance band edges of core semiconductor QDs are located within the energy gap of the shell semiconductor QDs. In this case, an electron-hole (e-h) pair excited near the interface tends to localize in the core, which provides the lowest energy states for both the electron and hole $[19,20]$.

Type-II core/shell QDs have staggered band offsets, namely, a higher valence band or lower conduction band in the shell than in the core. As a result, the wave functions of the electron and hole exist separately, which leads to many novel properties, for example, the red shift of the emission and a long decay lifetime [21]. Interesting opportunities are associated with the use of the type-II regime in colloidal structures which allow, for example, controlling of both single [22] and multiexciton [23] lifetimes. Furthermore, spatial separation between positive and negative charges produced in these structures can simplify applications of NCs in photovoltaic technologies [24].

In the present work, an effective method for producing a composite of quantum dots consisting of CdSe (core) with CdS (shell) is applied. This composite of nanoparticles has been synthesized using modified organometallic precursors. The obtained nanoparticles of $\mathrm{CdSe}$ core and $\mathrm{CdSe} / \mathrm{CdS}$ core/shell NCs were characterized at room-temperature using X-ray diffraction XRD,
UV-Vis absorption, photoluminescence PL spectroscopy and high resolution electron microscopy HRTEM.

\section{Experimental}

\subsection{Chemicals}

Cadmium oxide ( $\mathrm{CdO} 98.9 \%$ ), was obtained from Fluka. Selenium powder (Se $99 \%$ ), sulfur powder (S 99.5\%), hexadecylamine (HDA $97 \%$ ), trioctylphosphine (TOP $90 \%$ ), trioctylphosphine oxide (TOPO $97 \%$ ) were purchased from Aldrich. Oleic acid (OA) $98 \%$, stearic acid $98 \%$, acetone $98 \%$, toluene $99 \%$, methanol $99 \%$ were from United Chemical Lab. All chemicals and solvents were used as received without additional purification. The synthesis of $\mathrm{CdSe}, \mathrm{CdS}$ and $\mathrm{CdSe} / \mathrm{CdS}$ was carried out by a modified organometallic method [5]. In the experiments, TOP was used as the ligand of the Se precursor, and OA was employed as the ligand of $\mathrm{Cd}$ precursor.

\subsection{Synthesis of CdSe (core) nanoparti- cles}

$\mathrm{CdO}(0.3 \mathrm{~g})$ and oleic acid $(3 \mathrm{~mL})$ were heated up to $170{ }^{\circ} \mathrm{C}$ under vigorous stirring to obtain a clear solution of cadmium oleate, TOPO $(2 \mathrm{~g})$ and HDA ( $2 \mathrm{~g})$ as passivating medium were added to the cadmium oleate solution then heated up to $220{ }^{\circ} \mathrm{C}$. TOP-Se $(0.3 \mathrm{~g}$ Se in $4 \mathrm{~mL}$ TOP $)$ was rapidly injected to that mixture. Five samples of CdSe NPs were collected at different time intervals (from $5 \mathrm{~min}$ to $30 \mathrm{~min}$ ) and labeled (A1-A5), respectively. These aliquots were cooled down by dissolving them in toluene. After that, they were kept at room temperature for 3 hours, until the orange precipitate was formed. The samples were centrifuged at $4000 \mathrm{rpm}$, for $15 \mathrm{~min}$ and the obtained precipitates were washed three times by adding equal ratio of acetone and methanol. $\mathrm{Nu}-$ cleation and growth were previously discussed in detail by Lamer et al. [25]. 


\subsection{Synthesis of $\mathrm{CdSe} / \mathrm{CdS}$ core/shell nanoparticles}

The orange precipitate containing CdSe QDs core was re-prepared in a three-neck flask, as described in Section 2.2. A small sample was taken during the process and characterized by XRD; it was corresponding to the smaller collected sample A1 (the first drawn of the CdSe core). $0.3 \mathrm{~g}$ of elemental $\mathrm{S}$ was dissolved in a clean vessel containing $4 \mathrm{~mL}$ of TOP to achieve TOP-S solution. This solution (TOP-S) and the mixture of $\mathrm{Cd}$ stearate + TOPO + HDA were injected slowly to the CdSe, already prepared in the three-neck flask from both sides. In order to demonstrate the possibility to control the final particle size, the samples were collected in different times. Four aliquot samples of $\mathrm{CdSe} / \mathrm{CdS}$ were withdrawn at different times from $5 \mathrm{~min}$ to $20 \mathrm{~min}$ and labeled as $\mathrm{S} 1, \mathrm{~S} 2$, S3 and S4, respectively. These aliquots were immediately cooled by toluene to monitor UV-Vis absorbance and fluorescence spectra. Then the samples were centrifuged at $4000 \mathrm{rpm}$ for $15 \mathrm{~min}$ and the obtained precipitates were washed three times by adding equal ratio of acetone and methanol. Sample S4 was characterized by XRD to confirm the crystalline phase and size.

\subsection{Synthesis of CdS nanoparticles}

$\mathrm{CdO}(0.3 \mathrm{~g})$ was added to oleic acid $(3 \mathrm{~mL})$ to get $\mathrm{Cd}$ oleate, and then the mixture was heated up to $170{ }^{\circ} \mathrm{C}$. TOPO and HDA were added to the reaction mixture; then temperature was increased up to $220{ }^{\circ} \mathrm{C}$. When the solution became transparent, the temperature was decreased to $190{ }^{\circ} \mathrm{C}$. At this temperature, TOP-S solution was injected into the hot flask. The solution turned to yellow color due to the formation of $\mathrm{CdS}$. The reaction mixture was cooled down by dissolving it in toluene. After that, it was kept at room temperature for 3 hours until precipitate was formed. The samples were centrifuged at $4000 \mathrm{rpm}$ for $15 \mathrm{~min}$ and the obtained precipitate was washed three times by acetone and methanol. The obtained CdS powder was characterized by XRD to determine the crystalline phase and size of the nanoparticles.

\subsection{Measurements}

X-ray diffraction (XRD) spectra were recorded at room temperature using Philips PW 1710 diffractometer with $\mathrm{CuK} \alpha$ radiation with $\lambda=1.5406 \AA$ and diffraction angle $2 \theta$ from $10^{\circ}$ to $90^{\circ}$. The images of nanocrystals were taken by HRTEM JEM-2100 (JOEL) operated at $200 \mathrm{kV}$ and equipped with an EDS probe. For obtaining the TEM images, the prepared samples were dispersed ultrasonically in absolute toluene and then the colloid was dropped onto $\mathrm{Cu}$-grid coated with an amorphous carbon film and dried. The absorbance of QDs suspensions was measured by using a Perkin Elmer Lambda 750 UV-Vis spectrophotometer in the wavelength range of $200 \mathrm{~nm}$ to $900 \mathrm{~nm}$. The fluorescence spectra were measured by using a fluorescence spectrometer JASCO-FP-6300 (at excitation wavelength $450 \mathrm{~nm}$ ). Quartz cells were used in both absorption and emission measurements.

\section{Results and discussion}

\subsection{Structural and morphological proper- ties of CdSe nanocrystals}

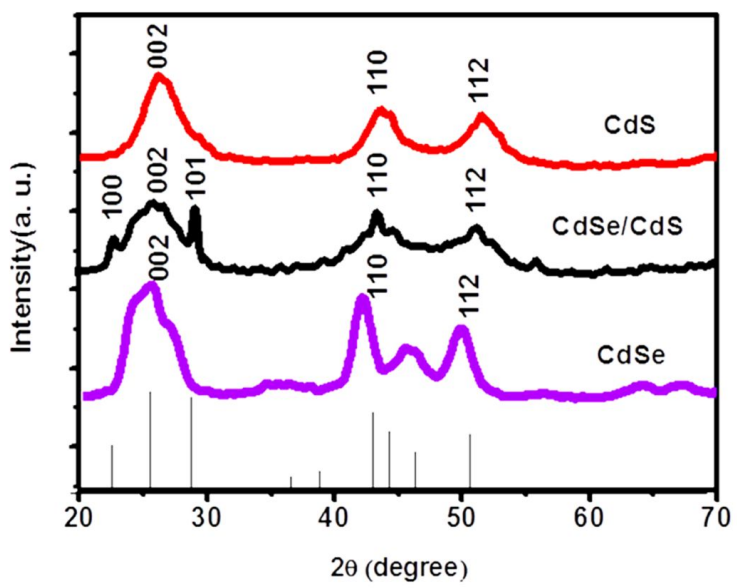

Fig. 1. XRD patterns of synthesized CdSe, CdSe/CdS and CdS nanocrystals capped with TOPO molecules.

Fig. 1 displays diffraction patterns of the synthesized CdSe core (sample A1), CdSe/CdS core/shell (sample S4) and CdS shell. Information 
about the lattice parameters of the core, core/shell, and shell is reported in Table 1. The width of the peaks indicates the formation of nanoparticles. In case of $\mathrm{CdSe} / \mathrm{CdS}$ nanoparticles, the powder diffraction pattern shows a wider peak width. The position of the peak is shifted toward $\mathrm{CdS}$ values. The CdSe and CdS diffraction patterns exhibit peak positions corresponding to these of bulk wurtzite crystal structures. There are almost no qualitative differences in structure between the CdS nanoparticles and $\mathrm{CdSe} / \mathrm{CdS}$ composite particles. The average crystallite size of the $\mathrm{CdSe}, \mathrm{CdSe} / \mathrm{CdS}$ and $\mathrm{CdS}$ QDs was calculated from the peak width at half-maximum of $\left(\begin{array}{lll}0 & 0 & 2\end{array}\right)$ plane, using the Sherrer equation [26]:

$$
D=\frac{0.9 \lambda}{\beta \cos \theta}
$$

where $\lambda$ is the $\mathrm{X}$-ray wavelength of $\mathrm{CuK} \alpha$ radiation $(\lambda=1.5406 \AA$ ),$\theta$ is the Bragg diffraction angle (in radian) and $\beta$ is the integral breadth (i.e. area under the curve divided by maximum height, in radian). The average size of $\mathrm{CdSe}, \mathrm{CdSe} / \mathrm{CdS}$ and $\mathrm{CdS}$ is about $2.73 \mathrm{~nm}, 3.64 \mathrm{~nm}$ and $2.51 \mathrm{~nm}$, respectively.
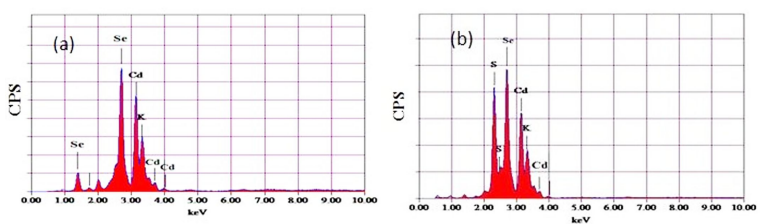

Fig. 2. EDS spectra of (a) $\mathrm{CdSe}$, (b) $\mathrm{CdSe} / \mathrm{CdS}$ nanoparticles.

Fig. 2 shows energy dispersive spectra of $\mathrm{CdSe}$ and $\mathrm{CdSe} / \mathrm{CdS}$ nanoparticles which suggest chemical purity and stoichiometry of the samples. The strong peaks related to $\mathrm{Cd}, \mathrm{Se}$ and $\mathrm{S}$ are found in the spectrum. In Fig. 2a, the elemental atomic percentage in $\mathrm{CdSe}$ is $\mathrm{Cd}(48.31 \%)$ and $\mathrm{Se}$ $(48.73 \%)$. Fig. $2 \mathrm{~b}$ confirms the presence of sulfur and cadmium elements S (24.60\%), Cd (53.23\%). The detected potassium element $\mathrm{K}$ is attributed to glass substrate.

High resolution transmission electron microscopy (HRTEM) images and size distribution diagrams of $\mathrm{CdSe}$ and $\mathrm{CdSe} / \mathrm{CdS}$ composite

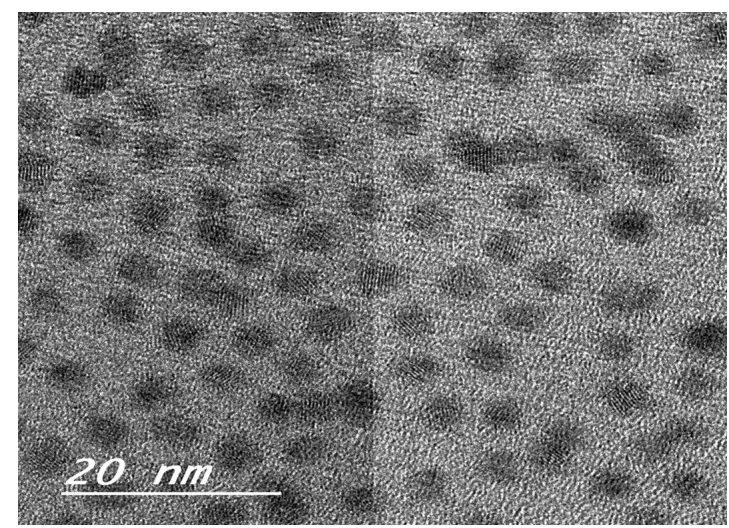

(a)
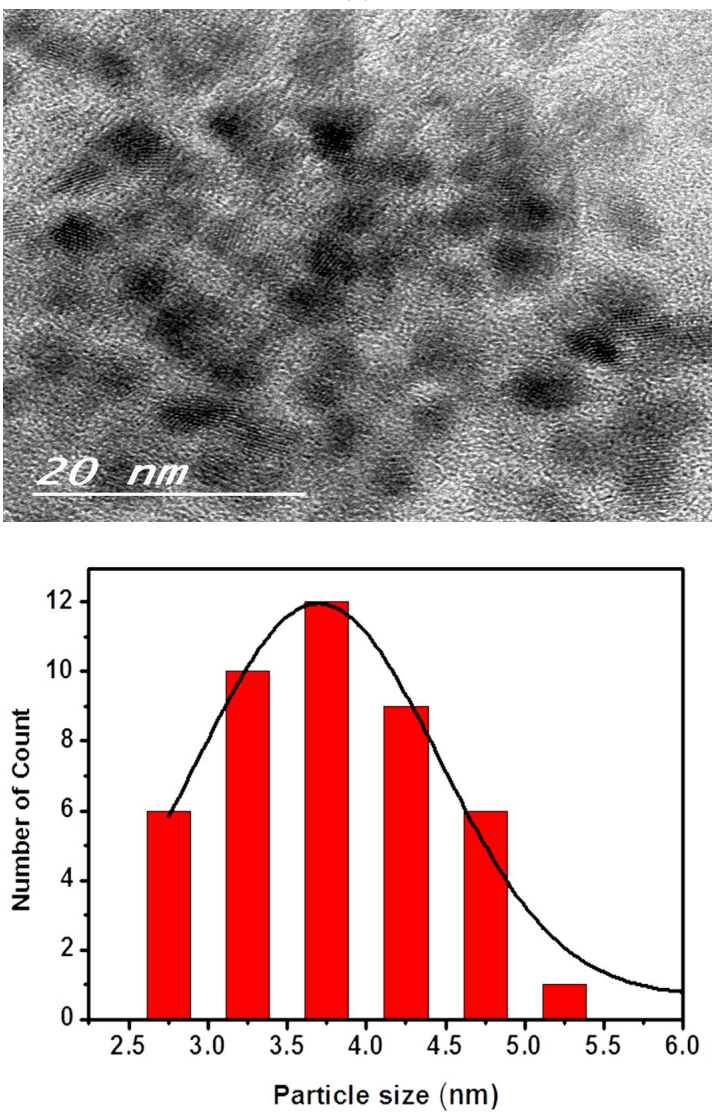

(b)

Fig. 3. Transmission electron images and size histograms for synthesized nanoparticles: (a) CdSe core, (b) CdSe/CdS core/shell.

nanoparticles are shown in Fig. 3. The shape of CdSe NPs is nearly spherical. In the HRTEM image, CdSe is displayed as a dark core surrounded by a gray shell indicating the structure of CdSe cores covered by the CdS shells (Fig. 3b). The core/shell 
Table 1. Results obtained from XRD for synthesized nanoparticles.

\begin{tabular}{ccccccc}
\hline Sample No. & Sample type & $2 \theta\left[^{\circ}\right]$ & \multicolumn{5}{c}{ FWHM $(\mathrm{h}$ k l) } & d-spacing X-ray size $[\mathrm{nm}]$ \\
\hline \hline A1 & CdSe (core) & 25.26 & 3.15 & 0002 & 0.36 & 2.73 \\
S4 & CdSe/CdS (core/shell) & 25.63 & 2.34 & 002 & 0.35 & 3.64 \\
CdS & CdS (Shell) & 26.483 .4 & 002 & 0.34 & 2.51 & \\
\hline
\end{tabular}

is clearly larger than the core. The size of prepared nanoparticles obtained from the histogram is $3.15 \pm 0.5 \mathrm{~nm}$ and $3.75 \pm 0.7 \mathrm{~nm}$ for CdSe and $\mathrm{CdSe} / \mathrm{CdS}$ core/shell, respectively, with the shell thickness $\sim 0.6 \mathrm{~nm}$.

The particle size measured from TEM micrograph is larger than that calculated from XRD. This might be explained by the fact that X-ray diffraction results are based on the mean size of a sample obtained from XRD pattern, which is smaller than that obtained from all the structural layers of the sample when using TEM. Also in XRD method, standard system errors have not been eliminated.

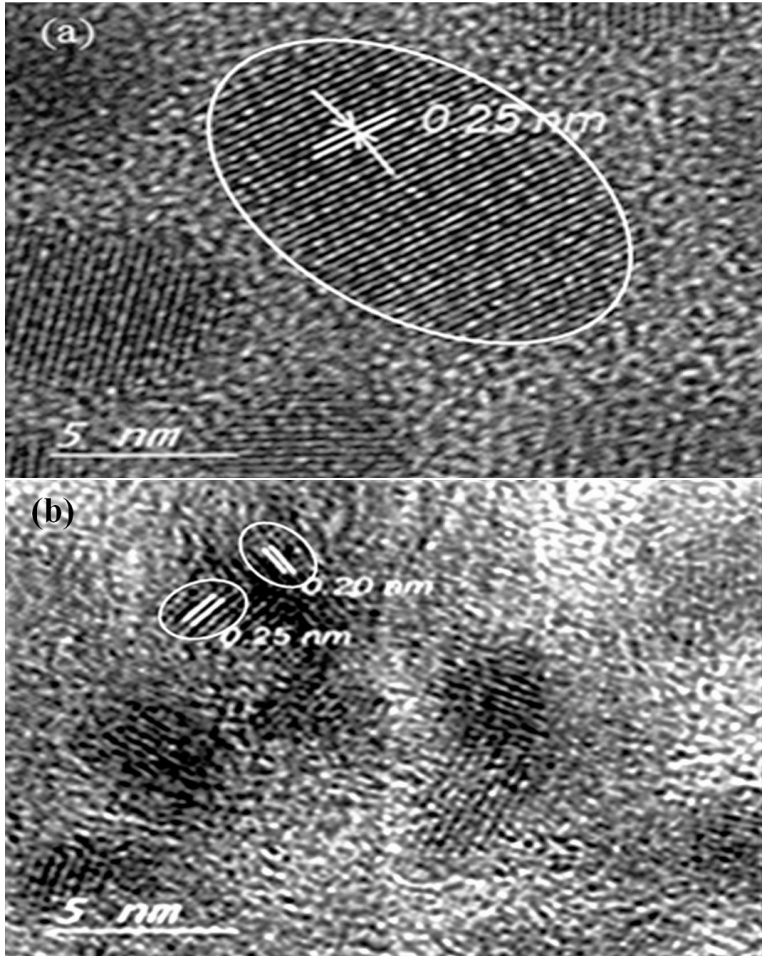

Fig. 4. HRTEM images of (a) CdSe nanocrystallite core and (b) $\mathrm{CdSe} / \mathrm{CdS}$ core/shell QDs.

The particles in the micrographs, Fig. 4, clearly reveal crystalline lattice fringes. The lattice planes

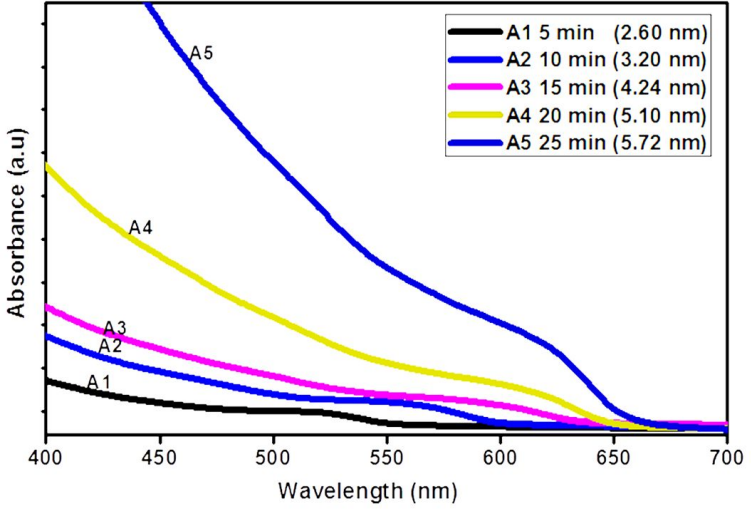

Fig. 5. UV-Vis spectra of the CdSe for different samples obtained in various growth times.

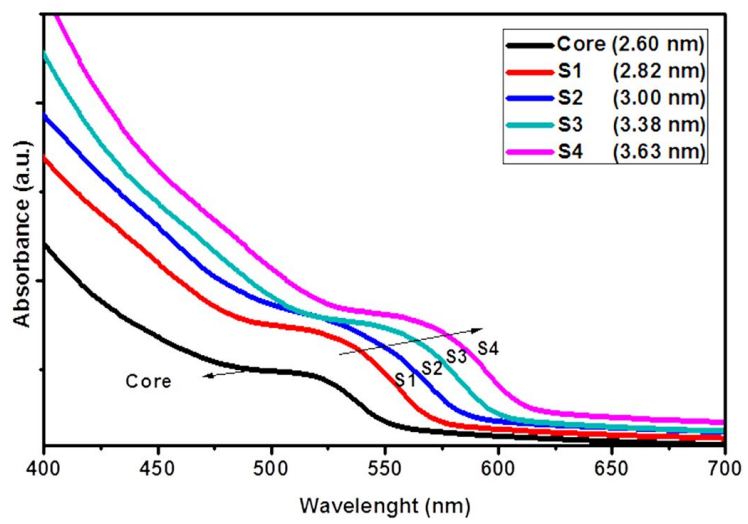

Fig. 6. UV-Vis spectra of the CdSe/CdS core/shell of various sizes.

distance is identical to hexagonal CdSe. However, the lattice fringes observed in the core/shell (Fig. 4b), persist throughout the entire nanocrystal, indicating epitaxial growth. The obtained value of d-spacing calculated for CdSe equals to $0.25 \mathrm{~nm}$, corresponding to (l 102 ) plane, while the d-spacing for $\mathrm{CdS}$ shell equals to $0.20 \mathrm{~nm}$, corresponding to the $\left(\begin{array}{lll}1 & 1 & 0\end{array}\right)$ plane. The TEM images give more accurate size than that calculated using XRD data. 


\subsection{Optical properties}

The optical properties of the CdSe and $\mathrm{CdSe} / \mathrm{CdS}$ quantum dots were extensively characterized by UV-Vis absorption and PL spectroscopy.

Fig. 5 shows the shift of the peaks positions and the shapes of the UV-Vis absorption spectra for $\mathrm{CdSe}$ during the whole reaction process. The positions of the peaks are located at the wavelength range of $523 \mathrm{~nm}$ to $622 \mathrm{~nm}$ and shifted toward longer wavelengths when the reaction time was increased from $5 \mathrm{~min}$ to $30 \mathrm{~min}$. From the peak position, one can roughly estimate the average size of CdSe QDs from the following equation (Yu et al. [27]):

$$
\begin{aligned}
& D\left(\frac{\text { diameter }}{n m}\right)=\left(1.6122 \times 10^{-9}\right) \lambda^{4} \\
& -\left(2.6575 \times 10^{-4}\right) \lambda^{3}+\left(1.6242 \times 10^{-3}\right) \lambda^{2} \\
& -(0.4277) \lambda+41.57
\end{aligned}
$$

where $D[\mathrm{~nm}]$ is the size of a given nanocrystal sample and $\lambda[\mathrm{nm}]$ is the wavelength of the first excitonic absorption peak of the corresponding sample. The calculated size of the prepared CdSe nanocrystals corresponding to $\lambda_{\max }$ of the first absorption peak ranged from $2.60 \mathrm{~nm}$ to $5.72 \mathrm{~nm}$ as reported in Table 2.

The shell is used to passivate the surface of the core to improve its overall optical properties. Another role of the shell is to separate the more optically active core surface from its surrounding environment. The optical spectra of $\mathrm{CdSe} / \mathrm{CdS}$ core/shell are shown in Fig. 6 together with that of CdSe core. Due to the growth of CdS shell, the absorption spectra roughly maintained their overall shape but shifted to higher wavelength (lower energies) at higher shell thickness. The particle size of $\mathrm{CdSe} / \mathrm{CdS}$ core/shell increased from $2.82 \mathrm{~nm}$ to $3.63 \mathrm{~nm}$ whereas the absorption peaks shifted from $538 \mathrm{~nm}$ to $574 \mathrm{~nm}$, respectively.

The CdS shell affected the electronic state of the CdSe core, as the electron from the core could easily be excited to the CdS shell while the holes remained inside the core because of their effective mass. According to Liu et al. [28], the separation of the electron and hole lowers the confinement energy of the exciton leading to the red shift observed in the absorption spectra for $\mathrm{CdSe} / \mathrm{CdS}$ core/shell nanocrystal. In this study, comparative calculation results of the mean particle size of CdSe and $\mathrm{CdSe} / \mathrm{CdS}$ NPs obtained from the powder XRD investigation, direct TEM measurement and optical spectra parameters are reported in Table 3. The particle size measured from TEM micrographs is larger than the size value calculated from XRD data, and the size corresponding to $\lambda_{\max }$ of absorption spectra.

In the $\mathrm{CdSe} / \mathrm{CdS}$ structure, the $\mathrm{CdS}$ shell is a higher band gap material than that of the core. The optical band gap $\mathrm{E}_{\mathrm{g}}$ of the CdSe core and of three $\mathrm{CdSe} / \mathrm{CdS}$ core/shell NPs with different sizes was calculated from the UV-Vis spectrum using the Tauc relation [29]:

$$
(\alpha h v)=B\left(h v-E_{g}\right)^{r}
$$

where $\alpha$ is the absorption coefficient, hv is the photon energy, $\mathrm{B}$ is the band tailing parameter, $\mathrm{E}_{\mathrm{g}}$ is the optical band gap of the nanoparticle, and $r=1 / 2$ for direct band gap and $r=2$ for indirect band gap.

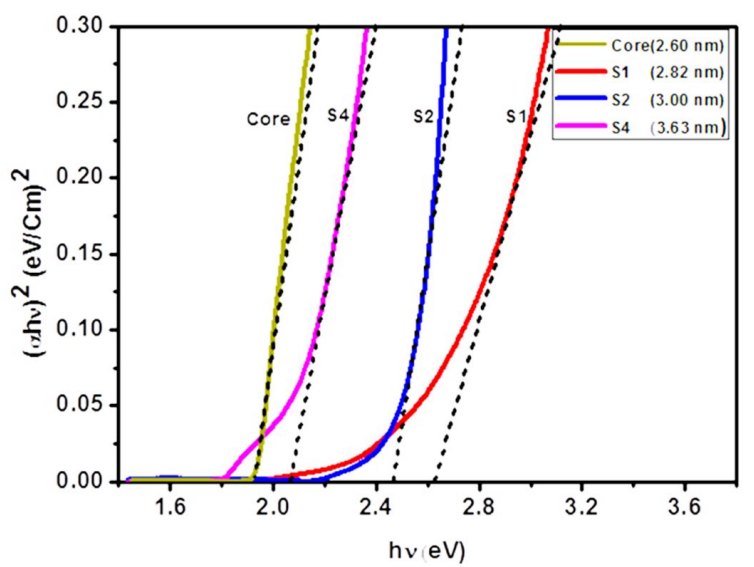

Fig. 7. Different plots of $(\alpha h v)^{2}$ vs. hv, for CdSe core and $\mathrm{CdSe} / \mathrm{CdS}$ core/shell nanoparticles with different sizes.

The energy intercept of a plot $(\alpha \mathrm{h} v)^{2}$ vs. $\mathrm{h} v$ yields $\mathrm{E}_{\mathrm{g}}$ as shown in Fig. 7 and reported in Table 4 . The optical band gap decreases from $2.62 \mathrm{eV}$ to $2.07 \mathrm{eV}$ with increasing $\mathrm{CdSe} / \mathrm{CdS}$ particle size due to the change in the shell thickness. It is noticed that the band gap values are effectively tuned by the particle size. Therefore, there is an enhancement 
Table 2. Spectroscopy parameters of CdSe and CdSe/CdS nanocrystals.

\begin{tabular}{|c|c|c|c|c|c|c|c|c|c|}
\hline \multicolumn{5}{|c|}{ CdSe core } & \multicolumn{5}{|c|}{$\mathrm{CdSe} / \mathrm{CdS}$ core/shell } \\
\hline $\begin{array}{c}\text { Sample } \\
\text { No. }\end{array}$ & $\begin{array}{l}\text { Collecting } \\
\text { time [min] }\end{array}$ & $\begin{array}{c}\text { Absorption } \\
\text { peak [nm] }\end{array}$ & $\begin{array}{l}\text { Emission } \\
\text { peak }[\mathrm{nm}]\end{array}$ & $\begin{array}{c}\text { Particle } \\
\text { size }[\mathrm{nm}]\end{array}$ & $\begin{array}{c}\text { Sample } \\
\text { No. }\end{array}$ & $\begin{array}{l}\text { Collecting } \\
\text { time [min] }\end{array}$ & $\begin{array}{c}\text { Absorption } \\
\text { peak [nm] }\end{array}$ & $\begin{array}{l}\text { Emission } \\
\text { peak }[\mathrm{nm}]\end{array}$ & $\begin{array}{c}\text { Particle } \\
\text { size }[\mathrm{nm}]\end{array}$ \\
\hline A1 & 5 & 523 & 505 & 2.60 & S1 & 5 & 538 & 504 & 2.82 \\
\hline A2 & 10 & 559 & 512 & 3.24 . & S2 & 10 & 548 & 517 & 3.00 \\
\hline A3 & 15 & 592 & 516 & 4.25 & S3 & 15 & 565 & - & 3.38 \\
\hline A4 & 20 & 611 & 518 & 5.11 & S4 & 20 & 574 & - & 3.63 \\
\hline A5 & 30 & 622 & 510 & 5.72 & - & - & - & - & \\
\hline
\end{tabular}

Table 3. Values of particle size of prepared nanocrystals obtained by different methods.

\begin{tabular}{ccccc}
\hline $\begin{array}{c}\text { Sample } \\
\text { No. }\end{array}$ & $\begin{array}{c}\text { Sample } \\
\text { type }\end{array}$ & $\begin{array}{c}\text { X-ray } \\
\text { size }[\mathrm{nm}]\end{array}$ & $\begin{array}{c}\text { Absorption particle size } \\
\text { by Yu. eq. [nm] }\end{array}$ & size [nm] \\
\hline \hline A1 & CdSe (core) & 2.73 & 2.6 & $3.15 \pm 0.5$ \\
S4 & CdSe/CdS (core/shell) & 3.64 & 3.63 & $3.75 \pm 0.7$ \\
\hline
\end{tabular}

of optical band gap around $0.42 \mathrm{eV}$. The change in $\mathrm{E}_{\mathrm{g}}$ with the size is attributed to quantum confinement effect.

The absorption edge of $\mathrm{CdSe} / \mathrm{CdS}$ core/shell is red shifted compared to $\mathrm{CdS}$, as the total size of the nanoparticles is larger than that of the core. This allows further delocalization of electrons wave function and creates red shifts of the band edge transition (size-effect). It is noticed that the value of the band gap of the synthesized CdSe, $\mathrm{E}_{\mathrm{g}}$, equals to $1.98 \mathrm{eV}$, which is significantly higher than the CdSe bulk value of $1.74 \mathrm{eV}$, proving that the CdSe QDs were effectively synthesized.

Table 4. The change of optical parameters with particles sizes of $\mathrm{CdSe} / \mathrm{CdS}$ nanoparticles.

\begin{tabular}{cccc}
\hline Sample & $\begin{array}{c}\text { Particle } \\
\text { size }[\mathrm{nm}]\end{array}$ & $\begin{array}{c}\lambda_{\max } \\
{[\mathrm{nm}]}\end{array}$ & $\begin{array}{c}\mathrm{E}_{\mathrm{g}} \\
{[\mathrm{eV}]}\end{array}$ \\
\hline \hline $\mathrm{S} 1$ & 2.82 & 538 & 2.62 \\
$\mathrm{~S} 2$ & 3 & 548 & 2.47 \\
$\mathrm{~S} 4$ & 3.63 & 574 & 2.07 \\
\hline
\end{tabular}

The photo-luminescent (PL) intensity of CdSe samples with various NPs sizes has been measured. A slight red shift of the maximum of the band edge is shown in Fig. 8. All the spectra consist of a single band associated with the band edge recombination.

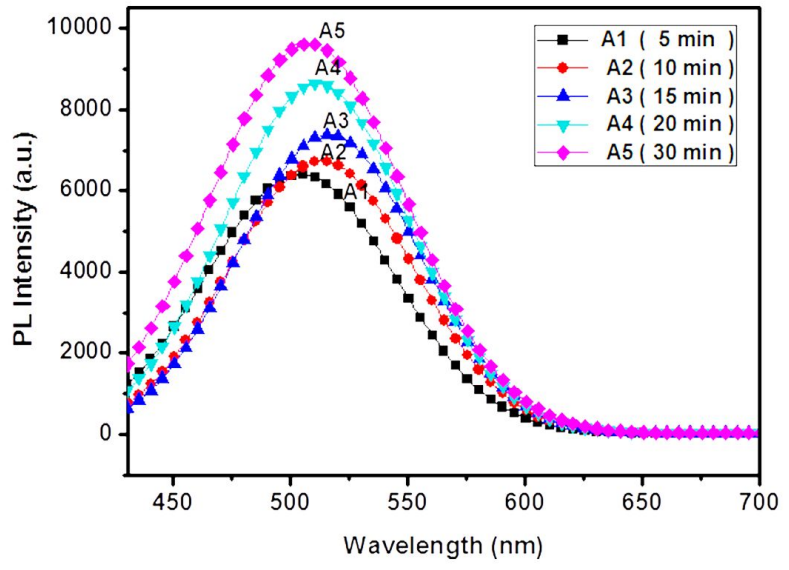

Fig. 8. The PL spectra of as-prepared TOPO capped CdSe NPs obtained at different times.

The emission band maximum is observed between $505 \mathrm{~nm}$ and $510 \mathrm{~nm}$ for various sizes NPs, ranging from $2.60 \mathrm{~nm}$ to $5.72 \mathrm{~nm}$, respectively. The PL intesity increases with size increase.

The PL spectra of the core/shell structures with different sizes are shown in Fig. 9. The thicker the CdS shell covering the CdSe core, the more emission maximum is shifted to higher wavelength (red shift $13 \mathrm{~nm}$ ). In the present investigation, room temperature fluorescence spectra were measured at an excitation wavelength of $\lambda_{\mathrm{ex}}=450 \mathrm{~nm}$. 


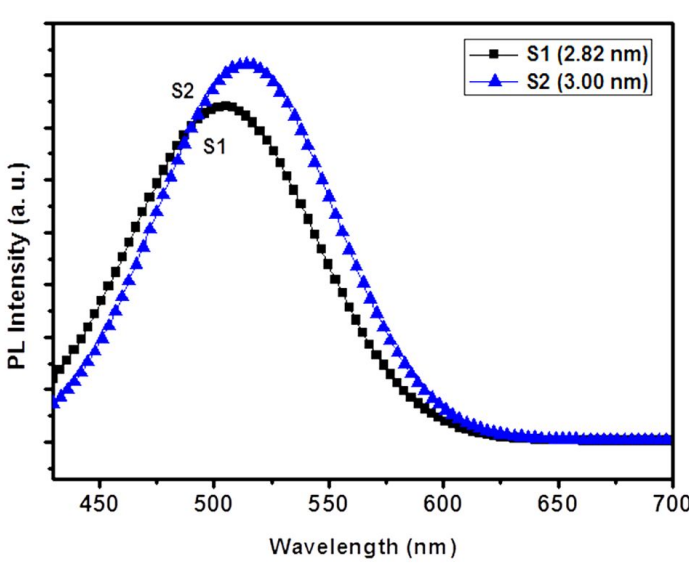

Fig. 9. PL spectra of $\mathrm{CdSe} / \mathrm{CdS}$ with different nanoparticle sizes.

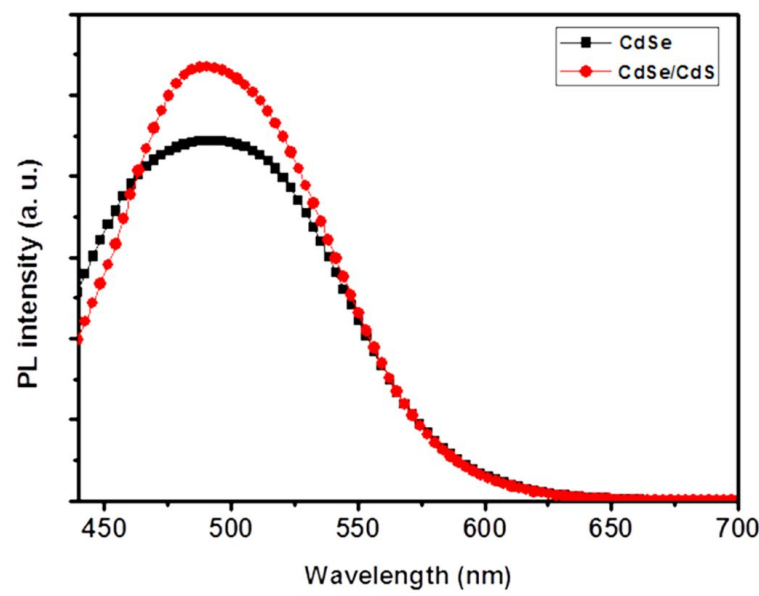

Fig. 10. The PL spectra of $\mathrm{CdSe}$ and CdSe/CdS core/shell nanocrystals.

The PL intensity of CdSe QDs increases several times when the CdSe cores are covered with a shell of high band gap material like CdS to form a $\mathrm{CdSe} / \mathrm{CdS}$ core/shell structure. Emission characteristics of $\mathrm{CdSe} / \mathrm{CdS}$ core/shell QDs are well known to depend strongly upon the size of the CdSe core [30].

The emission spectra of CdSe and $\mathrm{CdSe} / \mathrm{CdS}$ nanoparticles are characterized by different intensities, due to the growth of $\mathrm{CdS}$ shell on the CdSe core (Fig. 10). The quantum yield of pure CdSe nanoparticles was found to be $30 \%$ and increased with addition of $\mathrm{CdS}$, approaching a value of $40 \%$ depending on particle sizes.

\section{Conclusions}

The CdSe core and $\mathrm{CdSe} / \mathrm{CdS}$ core/shell quantum dots were produced using a modified organometallic method and then characterized by various procedures. XRD study confirmed the hexagonal phase of the synthesized particles. The particle sizes were calculated using Debye -Sherrer equation. The size of CdSe nanocrystalline powder was about $2.73 \mathrm{~nm}$ for CdSe core (Sample A1) and $3.64 \mathrm{~nm}$ for CdSe/CdS, (Sample S4). TEM images of $\mathrm{CdSe}$ and $\mathrm{CdSe} / \mathrm{CdS} \mathrm{NCs}$ revealed their crystalline structure and approximately spherical shape. The morphological properties were assessed by TEM-EDS analysis and a comparative calculation of particle size of CdSe and CdSe/CdS NPs obtained using powder XRD procedure, direct TEM measurement and optical spectra parameters.

The optical properties of the nanostructured particles were extensively characterized by UV-Vis absorption spectroscopy and PL to study the influence of $\mathrm{CdS}$ shell on the optical properties of $\mathrm{CdSe}$ core. The results evidenced that $\mathrm{CdSe} / \mathrm{CdS}$ core/shell structure was formed with enhanced fluorescence behavior in comparison to $\mathrm{CdSe}$ core. The weak broad absorption peaks appeared for CdSe core in the size range of $2.60 \mathrm{~nm}$ to $5.72 \mathrm{~nm}$ and for $\mathrm{CdSe} / \mathrm{CdS}$ core/shell in the size range from $2.82 \mathrm{~nm}$ to $3.63 \mathrm{~nm}$. These peaks were blue-shifted gradually as the particle size decreased indicating quantum size effect due to formation of smaller particles. The optical band gap of NCs material depends on the particle radius because of the quantum confinement effect. The quantum confinement effect is observed when the size of a particle is small compared to the wavelength of electron. If the size of a quantum dot is smaller than that of electron with the Bohr radius $(3.15<6 \mathrm{~nm}$ for $\mathrm{CdSe}$ ), then confinement occurs leading to a transition from continuous to discrete energy. It was noticed that the band gap values of prepared samples are effectively tuned by the particle size. Therefore, there was an enhancement of optical band gap around $0.42 \mathrm{eV}$ for the studied $\mathrm{CdSe} / \mathrm{CdS}$ NCs.

\section{References}

[1] Steigerwald M.L., Polyhedron, 8 (1994), 1245. 
[2] Mansur H.S., Wiley Interdiscip. Rev. Nanomed. Nanobiotechnol., 2 (2010), 113.

[3] Park J., Lee K.H., Galloway J.F., Searson P.C., J. Phys. Chem., 46 (2008), 17849.

[4] Eychmüller A., Rogach A.L., Pure Appl. Chem., $1-2$ (2000), 179

[5] Murry C.B., Norris D.J., Bawendi M.G., J. Am. Chem. Soc., 19 (1993), 8706.

[6] Embden J.V., JasieniaK J., Gomez D.E., MulVANey P., Giersig M., Aust. J. Chem., 7 (2007), 458.

[7] Harrison M.T., Kershaw S.V., Burt M.G., EyChMuller A., Weller H., Rogach A.L., Mater. Sci. Eng. B-Adv., 69 (2000), 355.

[8] Sharm N., Vats T., Dhenadhayalan N., RamaMURThy P., Narula A.K., Sol. Energ. Mater. Sol. C., 100 (2012), 6

[9] Neeleshwar S., Chen C.L., TAsi C.B., Chenmy.Y., Phys. Rev. B, 20 (2005), 201307(R).

[10] Liaw Y.F., Li W.J., J. Zhejiang Uni. Sci. A, 9 (2007), 133.

[11] Sun M., YU H., YANG W., QI L., YANG F., YANG X., Colloids Surf. A Physicochem. Eng. Asp., 1 - 3 (2009), 91.

[12] Yang D., Chen Q., Xu S., J. Lumin., 2 (2007), 853.

[13] Talapin D.V., Rogach A.L., Kormowski A., HAASE M., Weller H., Nano Lett., 4 (2001), 207.

[14] Tian Y., Newton T., Kotov N.A., Guldi D.M., FEndler J., J. Chem. Phys., 21 (1996), 8927.

[15] Youn H.C., Baral S., Fendler J.H., J. Phys. Chem., 22 (1988), 6320.

[16] Kortan A.R., Hull R., Opila R.L., Bawendi M.G., Steigerwald M.L., Carroll P.J., Brus L.E., J. Am. Chem. Soc., 4 (1990), 1327.
[17] Mews A., Eychmuller A., Giersig M. Schooss D., Weller H., J. Phys. Chem., 3 (1994), 934.

[18] Hines M.A., Guyot-Sionnest P., J. Phys. Chem., 2 (1996), 468.

[19] Klimov V.I., Nanocrystal quantum dots, Taylor \& Francis Group, New York, 2010.

[20] Ledentsov N.N., Semicond. News, 2 (2001), 22.

[21] Klimov V.I., Mikhailovsky A.A., XU S., Malko A., Hollingsworth J.A., Leatherdale C.A., Eisler H., BAWEndi M.G., Science, 5490 (2000), 314.

[22] Schaller R.D., Petruska M.A., Klimov V.I., J. Phys. Chem. B, 50 (2003), 13765.

[23] Htoon H., Hollingsworth J.A., Dickerson R., Klimov V.I., Phys. Rev. Lett., 22 (2003), 227401.

[24] Cao Y., Banin U., J. Am. Chem. Soc., 40 (2000), 9692.

[25] Lamer V.K., Dinegar R.H., J. Am. Chem. Soc., 11 (1950), 4847.

[26] KUMARAN S.M., GOPALAKRISHNAN R., J. SolGel. Sci. Technol., 2 (2012), 193.

[27] Yu W.W., Qu L., Guo W., Peng X., Chem. Mater., 14 (2003), 2854.

[28] LiU S.M., GuO H.Q., Zhang Z.H., LI R., ChEN W., WAng Z.G., Phys. E., 2 (2000), 174.

[29] Ethayaraja M., Ravikumar C., MuthukUMARAN D., DUTTA K., BANDYOPADHYAYA R., $J$. Phys. Chem., 8 (2007), 3246.

[30] NGuyen H.Q., Adv. Nat. Sci. Nanosci. Nanotechnol., 2 (2010), 025004.

Received 2016-12-29

Accepted 2018-10-03 